\title{
Autonomy and the limits of cognitive enhancement
}

\author{
Jonathan Lewis
}

Institute of Ethics, Faculty of Humanities and Social Sciences, Dublin City University, Dublin, Ireland

\section{Correspondence}

Jonathan Lewis, Institute of Ethics, Faculty of Humanities and Social Sciences, Dublin City University, All Hallows Campus, Dublin 9, Ireland.

Email: jonathan.lewis@dcu.ie

\begin{abstract}
In the debates regarding the ethics of human enhancement, proponents have found
Abstract
In the debates regarding the ethics of human enhancement, proponents have found it difficult to refute the concern, voiced by certain bioconservatives, that cognitive enhancement violates the autonomy of the enhanced. However, G. Owen Schaefer, Guy Kahane and Julian Savulescu have attempted not only to avoid autonomy-based bioconservative objections, but to argue that cognition-enhancing biomedical interventions can actually enhance autonomy. In response, this paper has two aims: firstly, to explore the limits of their argument; secondly, and more importantly, to develop a more complete understanding of autonomy and its relation to cognitive enhancement. By drawing a distinction between the capacity for autonomy and the exercise and achievement of autonomy, and by exploring the possible effects of cognitive enhancement on both competence and authenticity conditions for autonomy, the paper identifies and explains which dimensions of autonomy can and cannot, in principle, be enhanced via direct cognitive interventions. This allows us to draw conclusions regarding the limits of cognitive enhancement as a means for enhancing autonomy.
\end{abstract}

KEYWORDS

authenticity, autonomy, cognitive enhancement, competence, reasoning, relational autonomy

\section{1 | INTRODUCTION}

According to G. Owen Schaefer, Guy Kahane and Julian Savulescu, when cognitive and volitional limitations prevent healthy, cognitively unimpaired individuals from living what Savulescu has referred to as 'the best life', ${ }^{1}$ the solution is not paternalistic intervention. ${ }^{2}$ Instead, cosmetic neurological help should be provided to enhance core cognitive capacities, for example by way of nootropic drugs, surgery, neural implants, direct brain-computer interfaces or genetic engineering. The presumption here is not that there is a threshold of cognitive ability such that only those individuals who fall short stand to benefit from cognitive enhancement (CE). Rather, those that advocate for direct manipulations of brain structure via biomedical and technological means tend to appeal to a perfectionist view of cognitive function. Accordingly, we are all in a position to benefit from the amplification of our cognitive capacities. ${ }^{3}$

The problem is that although there has been strong support for CE via indirect interventions such as psychotherapy and education, some bioconservatives have objected to more unconventional approaches because they violate autonomy. ${ }^{4}$ According to Jürgen Habermas' critique of enhancement, with which Schaefer et al. explicitly engage, although 'we should come to the aid of others, and do all we can to improve the conditions of their lives', 'we are not permitted to determine, according to our own ideas about other people's future life, the range of opportunities these others will one day face in their attempt to give ethical shape to 
their own lives'. ${ }^{5}$ Focusing on genetic enhancement, he raises the concern that eugenic programming of desirable traits 'commits the person concerned to a specific life-project or, in any case, puts specific restrictions on his freedom to choose a life of his own' ${ }^{6}$ In effect, if an individual is genetically enhanced according to third-party prenatal design intentions, then that individual is no longer 'the undivided author of his own life'. 7 What has occurred is the 'alienating dilution or fracturing' of the child's identity to the degree that he is not able to authentically exercise his autonomy. ${ }^{8}$ In response, Schaefer, Kahane and Savulescu argue that if it can be shown that controversial direct modalities for amplifying cognition do, in fact, enhance autonomy, then bioconservatives would no longer have an autonomy-based reason to oppose them. ${ }^{9}$

Schaefer et al. acknowledge that if they are to present an autonomy-based case for $\mathrm{CE}$, then they need to make the nature of autonomy explicit. However, they recognize the difficulty of presenting an account of autonomy enhancement that satisfies the competing conditions of different theories of autonomy. ${ }^{10}$ Their solution involves identifying 'features common to all (or at least most) plausible conceptions of autonomy. ${ }^{11}$ They claim that 'most will accept that reasoning capacity is necessary for autonomy', where such a capacity is understood in terms of the cognitive capacities for 'deductive/ logical competence, comprehension (including the avoidance of false beliefs), and critical analysis'. ${ }^{12}$ They argue that if reasoning capacity is a necessary condition of autonomy, then inhibiting this capacity via 'brainwashing, psychological manipulation, deception, and lack of self-awareness' will generally inhibit autonomy. ${ }^{13}$ Improving reasoning capacity will, therefore, generally prevent these impediments. They claim that CE will improve reasoning capacity. Consequently, CE will generally improve autonomy.

The fundamental aim of this paper is to explore the limits of this argument and, more importantly, to develop a more complete understanding of autonomy and its relation to enhancement. The paper begins by situating Schaefer et al.'s approach to 'features common to all (or at least most) plausible conceptions of autonomy' in relation to the capacity-oriented competence model of autonomy traditionally employed in the context of patient consent (Section 2). It will be shown that there is a distinction to be made between autonomy understood in terms of the capacities for autonomous agency, that is, the capacity for autonomy, and autonomy understood as an individual's autonomous exercise of these capacities, that is, the exercise and achievement of autonomy (Section 3). The issue is that Habermas

\footnotetext{
${ }^{5}$ Habermas, J. (2003). The future of human nature. Cambridge, U.K.: Polity Press, pp. 89-90.

${ }^{6}$ Habermas, op. cit. note 5, p. 61

${ }^{7}$ Ibid: 63.

${ }^{8}$ Ibid: 82.

${ }^{9}$ Schaefer et al., op. cit. note 2, p. 135

${ }^{10}$ Ibid: 126.

${ }^{11}$ Ibid: 125.

${ }^{12}$ Ibid: $126-127$.

${ }^{13}$ Ibid: 127.
}

bioconservative concerns, which are also reflected in the contemporary empirical literature on enhancement, lead him to extend the discussion of autonomy beyond competency, encompassing matters relating to the authentic exercise of one's autonomy through those reasoning processes that give rise to one's behaviour. Although the point of this paper is not to argue for or against the reasonableness of Habermas' critique of enhancement, questions of authenticity are vital to determining the autonomy-enhancing limits of CE. In order to explain those limits, the following section (Section 4) will engage with relational conceptions of autonomy, for which authenticity conditions are as important to the capacity for, and exercise of, autonomy as competency conditions. I argue that although reasoning capacity is a necessary condition for the exercise and achievement of autonomy, we need a more complete understanding of autonomy, one that considers the relationships between competence, authenticity and enhancement, in order to successfully determine whether CE generally improves autonomy. In light of relational conceptions of autonomy, this paper shows that CE is not a sufficient condition for autonomy enhancement. Furthermore, there is evidence to suggest that it may not even be a necessary condition for the enhancement of an agent's exercise of her autonomy. By explaining the limits of $\mathrm{CE}$ as a means for autonomy enhancement, this paper complements Schaefer et al.'s approach, yet, simultaneously, extends the debates regarding the ethics of bioenhancement.

\section{2 | COMPETENCY AND THE CAPACITY FOR AUTONOMY}

Philosophical accounts of the nature of autonomy tend to focus on different specifications of two broad categories of conditions: competency and authenticity. In medical decision-making contexts, it is accepted that a competent person must have the capacities to comprehend information, critically reflect on and revise beliefs, and make a decision in the light of information. Similarly, for Schaefer et al., competency conditions refer to 'reasoning capacity', that is, the cognitive capacities needed for an individual 'to properly comprehend the options ahead of them, evaluate different options, deduce appropriate courses of action, weigh consequences, etc. ${ }^{14}$ These are the capacities for 'deductive/logical competence, comprehension (including the avoidance of false beliefs), and critical analysis', which, according to Schaefer et al., are taken to be 'generally-accepted constituents of autonomy, such that improving on those features is generally taken to improve people's autonomy'. ${ }^{15}$ Such an approach is an important premise in Savulescu's work on addiction and autonomy. ${ }^{16}$ Specifically, he adopts the competence model of autonomy, which is constituted solely by competency conditions, namely, the capacities to comprehend, retain,

\footnotetext{
${ }^{14}$ Schaefer et al., op. cit. note 2, p. 126.

${ }^{15}$ Ibid: $126-127$

${ }^{16}$ Foddy, B., \& Savulescu, J. (2006). Addiction and autonomy: Can addicted people consent to the prescription of their drug of addiction? Bioethics, 20(1), 1-15.
} 
reflect on and rationally manipulate information and communicate a choice. In philosophical terms, this is an account of the necessary conditions for autonomous agency, understood as the capacity for autonomy. ${ }^{17}$ Consequently, there is no explicit mention of authenticity, which, according to Schaefer et al., 'is a notoriously vague and underspecified notion, making the task of elucidating how autonomy might be enhanced quite difficult'. ${ }^{18}$ Furthermore, the capacity-oriented conception of autonomy has been viewed as the basis for the functional-augmentative approach to enhancement whereby, according to its proponents, enhancements in general are considered to be interventions that 'improve some capacity or function (such as cognition, vision, hearing, alertness) by increasing the ability of the function to do what it normally does. ${ }^{19}$

The concept of the competent agent has been a core feature of those debates in bioethics and medical ethics in which Schaefer, Kahane and Savulescu are immersed. It not only grounds traditional approaches to the principle of respect for patient autonomy in medical ethics and law, but, for the past two decades, and in conjunction with liberal principles, has set the regulatory and statutory parameters within which patients should be immune from paternalistic clinical interventions. ${ }^{20}$ For example, if we follow sections 2(1) and 3(1) of the U.K.'s Mental Capacity Act 2005, then, in order to consent to treatment, an adult patient is presumed to have the capacities to understand, retain, use and weigh up the information relevant to a decision and communicate the decision. The implication is that when a patient lacks deliberative competence capacities (at the time when a decision needs to be made), outside interference in the decision-making process is more likely to be justified. However, as John Coggon and José Miola have observed, the problem is that 'a bald reading of the statutory test for capacity suggests only that a patient need have the capacity to understand'. ${ }^{21}$ In light of developments in common law, 'a doctor cannot simply accept an apparent consent from a patient who has the capacity for understanding, if that consent is based on the patient's having made the decision in ignorance of important factors that would bear on the decision'. ${ }^{22}$ Consequently, the assumption is that if a doctor lists the risks inherent in a procedure and then allows the competent patient to make her own choice based on that information, her choice is rendered autonomous. Nevertheless, while disclosure of relevant information is part of facilitating autonomy, it is not in itself enough to ensure that the patient makes an autonomous choice. As Jules Holroyd observes, an agent's choice is autonomous when she exercises her competence

\footnotetext{
${ }^{17}$ Holroyd, J. (2009). Relational autonomy and paternalistic interventions. Res. Publica, $15,325$.

${ }^{18}$ Schaefer et al., op. cit. note 2, p. 125.

${ }^{19}$ Earp, B. D., Sandberg, A., Kahane, G., \& Savulescu, J. (2014). When is diminishment a form of enhancement? Rethinking the enhancement debate in biomedical ethics. Frontiers in Systems Neuroscience, 8(12), 2.

${ }^{20}$ For example, Dworkin, G. (1988). The theory and practice of autonomy. Cambridge, U.K.: Cambridge University Press.

${ }^{21}$ Coggon, J., \& Miola, J. (2011). Autonomy, liberty, and medical decision-making. Cambridge Law Journal, 70(3), 541.

${ }^{22}$ Ibid.
}

capacities in deciding what to do on some occasion, which may demand the satisfaction of additional conditions, such as those pertaining to the accuracy of her beliefs or the reasonableness of her deliberation. ${ }^{23}$ Consequently, the combination of common law, statutory duties and established medical jurisprudence amounts to some level of obligation to ensure that a patient's competence capacities are genuinely exercised in accordance with certain epistemic standards. As Coggon and Miola observe, 'there is a concern not just for the capacity for reason, but also for the effective use of it'. ${ }^{24}$

Schaefer et al. recognize that additional conditions need to be satisfied in order to render an agent's choice autonomous. Accordingly, they stress the importance for an agent to be able to reason 'rationally', 'properly' and 'soundly'. ${ }^{25}$ Insofar as 'they work by affecting individuals' internal psychology and ability to reason properly', Schaefer et al. consider cases of brainwashing, psychological manipulation and deception to be indicative of autonomy inhibition. ${ }^{26}$ Furthermore, they claim that when it comes to making autonomous choices, 'accuracy of beliefs' is particularly important in the sense that an agent has 'true beliefs' and 'correct comprehension of the world and themselves'. ${ }^{27}$ On the basis that 'autonomy involves choice between options for what one judges one ought to do', Schaefer et al. implicitly account for the relationship between autonomous agency and autonomous choice by incorporating both within the capacity for autonomy (thereby appealing to the functional-augmentative approach to enhancement). In other words, rather than attending to competency and authenticity conditions for the genuine exercise of an agent's capacity for autonomy when making a choice, Schaefer et al. put forward a rationalistic argument for CE whereby autonomous choice can be explained by appealing to 'reasoning capacity'. In short, improving an agent's cognitive capacities for autonomous agency will improve not only their ability to comprehend, retain, reflect on and rationally manipulate information, but also their capacity to reason 'rationally', 'properly' and 'soundly', thereby safeguarding the agent from paradigmatic cases of autonomy inhibition and rendering their choices autonomous.

\section{3 | AUTONOMY DISTINCTIONS IN THE LIGHT OF BIOCONSERVATIVE CONCERNS}

This brings us to another important distinction in discussions regarding autonomy: autonomous action, ${ }^{28}$ which, for reasons that will become clearer, I call the 'exercise and achievement of autonomy'. It concerns the individual's power to determine how she exercises her authority over her actions. In other words, an action that is directed

\footnotetext{
${ }^{23}$ Holroyd, op. cit. note 17, pp. 325-326.

${ }^{24}$ Coggon \& Miola, op. cit. note 21, p. 528.

${ }^{25}$ Schaefer et al., op. cit. note 2 , p. 127 .

${ }^{26}$ Ibid.

${ }^{27}$ Ibid: 129.

${ }^{28}$ Holroyd, op. cit. note 17 , p. 326.
} 
at some goal is more or less autonomous depending on the degree to which one is the 'power behind whatever reasoning directly gives rise to one's behaviour'. ${ }^{29}$ Although there is philosophical disagreement about what exactly constitutes this power, the point is that an agent's values and desires, which motivate her behaviour, can be more or less autonomous depending on whether the processes or volitional structures by which they come to be developed are truly her own. Here, competence considerations overlap with those more explicitly aligned with authenticity. In short, although the capacity for autonomy and the competency conditions that constitute that capacity are necessary for an agent's ability to govern her actions, they do not guarantee that she can authentically determine how she exercises her autonomy. ${ }^{30}$

In light of Schaefer et al.'s claim that CE will generally improve autonomy, we need to specify whether this means improving both the capacity for autonomy and exercises of autonomy. In the literature on moral enhancement, the same distinction has been made, specifically, between behaviour-oriented and capacity-oriented enhancement. ${ }^{31}$ As we have seen, Schaefer et al. are concerned with the capacity approach to autonomy. Consequently, the paradigmatic cases for autonomy inhibition are understood as those phenomena that undermine autonomy by inhibiting an individual's capacities to reason 'rationally', 'properly' and 'soundly'. If we assume that the concept of autonomy refers merely to the capacity for autonomy, of which reasoning capacity is a necessary but, on Schaefer et al.'s account, insufficient condition, then their argument that CE generally enhances autonomy seems plausible. However, as Brian D. Earp, Thomas Douglas and Julian Savulescu observe, on the capacity-oriented approach to enhancement, interventions amount to facilitation rather than to determination of the agent's behaviour. ${ }^{32}$ Nevertheless, if we are concerned with whether cognitively enhanced individuals behave more autonomously, then we also need to consider the relationships between CE, conditions of authenticity and the exercise of autonomy.

Before addressing these relationships in detail (Section 4), we might gain a better understanding of what precisely is at stake by considering some of the ways in which Habermas' autonomy-based critique of enhancement diverges from Schaefer et al.'s response to that same critique. The former's objection to genetic enhancement turns precisely on the question of whether genetically enhanced individuals have the power to govern their own actions. Thus, for Habermas, the concept of autonomy does not refer merely to the capacity for autonomy. He is concerned with whether a genetically

\footnotetext{
${ }^{29}$ Buss, S., \& Westlund, A. (2018). Personal autonomy. In E. N. Zalta (Ed.), The Stanford encyclopedia of philosophy. Retrieved from https://plato.stanford.edu/archives/spr2018/ entries/personal-autonomy/.

${ }^{30}$ Ibid.

${ }^{31}$ Raus, K., Focquaert, F., Schermer, M., Specker, J., \& Sterckx, S. (2014). On defining moral enhancement: A clarificatory taxonomy. Neuroethics, 7(3), 263-273.

${ }^{32}$ Earp, B. D., Douglas, T., \& Savulescu, J. (2017). Moral neuroenhancement. In S. Johnson $\&$ K. Rommelfanger (Eds.), The Routledge handbook of neuroethics (pp. 166-184). New York, NY: Routledge.
}

altered person has 'authorship of her own life' (in the sense that the reasoning that motivates her actions is authentic) or whether there has been an 'alienating dilution or fracturing' of her identity that thereby affects her ability to (precariously) achieve autonomy. ${ }^{33}$ Questions of authenticity and an agent's power to govern her actions have also been focal points in the empirical literature on enhancement. For instance, commentators on the ethics of deep brain stimulation (DBS)-a neurosurgical procedure that employs implanted electrodes to directly alter neural function and behaviourhave suggested that this specific form of CE intervention can lead to novel psychological characteristics, including reported experiences of self-estrangement and alienation, that directly influence the reasoning processes that give rise to an individual's behaviour. ${ }^{34}$ Whether such evidence can be generalized to show that specific cognition-enhancing interventions lead to the kinds of self-alienation constitutive of inauthenticity is, however, beyond the scope of this paper. ${ }^{35}$

When Schaefer et al. claim that 'even on the conceptions of autonomy (such as self-authorship) that critics of enhancement endorse, it is possible to have enhancements that promote autonomy and thus avoid their critiques, ${ }^{36}$ this claim accounts for only one dimension of autonomy: competence. On this account, CE improves components of the capacity for autonomy, including 'deductive/logical competence, comprehension (including the avoidance of false beliefs), and critical analysis'. According to Julian Savulescu and Rick Momeyer, rational belief is a necessary condition of autonomous choice. ${ }^{37}$ By improving an agent's capacities for 'deductive/logical competence, comprehension (including the avoidance of false beliefs), and critical analysis', an agent's ability to reason more rationally is also improved. It is in this specific sense that Schaefer et al. consider CE to enhance autonomy. By contrast, whether his bioconservative objection is reasonable or not, Habermas is concerned with the effects of enhancement on the agent's power to govern their behaviour. Such a concern is based on the fact that he considers the exercise and achievement of autonomy not to be solely determined

\footnotetext{
${ }^{33}$ Habermas, op. cit. note 5, p. 82.

${ }^{34}$ Maslen, H., Pugh, J., \& Savulescu, J. (2015). The ethics of deep brain stimulation for the treatment of anorexia nervosa. Neuroethics, 8, 215-230; Pugh, J., Pycroft, L., Sandberg, A., Aziz, T., \& Savulescu, J. (2018). Brainjacking in deep brain stimulation and autonomy. Ethics and Information Technology, 20(3), 219-232.

${ }^{35}$ In terms of the neuroethical literature on self-estrangement following DBS, and the implications for autonomy, see, Klaming, L., \& Haselager, P. (2010). Did my brain implant make me do it? Questions raised by DBS regarding psychological continuity, responsibility for action and mental competence. Neuroethics, 6, 527-539; Gilbert, F. (2013). Deep brain stimulation for treatment resistant depression: Postoperative feelings of self-estrangement, suicide attempt and impulsive-aggressive behaviours. Neuroethics, 6, 473-481; Lipsman, N., \& Glannon, W. (2013). Brain, mind and machine: What are the implications of deep brain stimulation for perceptions of personal identity, agency and free will? Bioethics, 27, 465-470; Gilbert, F. (2015). A threat to autonomy? The Intrusion of predictive brain implants. AJOB Neuroscience, 6(4), 4-11; Gilbert, F., Viaña, J. N. M., \& Ineichen, C. (2018). Deflating the 'DBS causes personality changes' bubble. Neuroethics. doi: 10.1007/s12152-018-9373-8; Gilbert, F., Cook, M., O'Brien, T., \& Illes, J. (2019). Embodiment and estrangement: Results from a first-in-human 'Intelligent brain computer interface' trial. Science and Engineering Ethics, 25(1), 83-96.

${ }^{36}$ Schaefer et al., op. cit. note 2, p. 135.

${ }^{37}$ Savulescu, J., \& Momeyer, R. (1997). Should informed consent be based on rational beliefs? Journal of Medical Ethics, 23, 282-288.
} 
by an agent's reasoning capacity, but also to require consideration of whether the appropriate socio-recognitive conditions obtain such that the reasoning processes that motivate the agent's actions are authentic. The following section will explore Schaefer et al.'s claims regarding autonomy inhibition in order to demonstrate the ways in which such claims are intimately related to questions of authenticity. By considering their paradigmatic cases of autonomy inhibition in light of certain relational conceptions of autonomy, the aim is to determine the extent to which CE can be claimed to enhance autonomy.

\section{4 | RELATIONAL AUTONOMY AS A CHALLENGE TO COGNITIVE ENHANCEMENT}

Despite Schaefer et al.'s aim to remain neutral between competing conceptions of autonomy, there are reasons to suggest that their specific approach to the 'features common to all (or at least most) plausible conceptions of autonomy' is, in fact, premised on a socially embedded conception of agency. In what follows, it will be shown that when it comes to exercising autonomy, Schaefer et al. imply that the power behind the reasoning processes that give rise to an agent's actions is dependent not only upon her reasoning capacity, but also upon socio-relational processes. ${ }^{38}$ By engaging with the distinctly relational dimension of their approach to autonomy inhibition, two authenticity issues will be identified on the basis of which we can draw conclusions regarding the limits of CE as a means for enhancing autonomy.

The first issue concerns the causally relational dimension of their approach to personal autonomy. We noted Schaefer et al.'s claim that the accuracy of an agent's beliefs about the world and herself is an important aspect of autonomous choice. They argue that autonomous choice 'requires individuals to have sufficiently developed capacities to assess a wide range of topics and situations' and to 'effectively evaluate the claims of others and recognize fallacious arguments'. ${ }^{39}$ The implication is that whether an agent behaves autonomously depends on whether she actually responds formally to those reasons that legitimize or invalidate the mental states that move her to act in a particular way, where, according to Schaefer et al., these reasons are grounded in facts about the agent and external reality. ${ }^{40}$ As we have seen, Schaefer et al. argue that paradigmatic cases of brainwashing, psychological manipulation and deception can affect an agent's autonomy by affecting her internal psychology and inhibiting her ability to reason properly. ${ }^{41}$ Specifically, they suggest that such cases undermine autonomy because they prevent an agent

\footnotetext{
${ }^{38}$ I would like to thank Julian Savulescu for stating, in response to this paper, that he agrees with this point.

${ }^{39}$ Schaefer et al., op. cit. note 2, p. 126.

${ }^{40}$ Buss \& Westlund (op. cit., note 29 ) observe that reasons are to be understood as external to mental states.

${ }^{41}$ Schaefer et al., op. cit. note 2, p. 127.
}

from being able to effectively attend to, evaluate and respond to a sufficiently broad range of reasons. ${ }^{42}$ What these paradigmatic cases of autonomy inhibition demonstrate is that an agent's reasoning capacity does not, on its own, guarantee her autonomy, because the reasoning processes that motivate behaviour can be affected by external forces. In other words, interpersonal relations can causally contribute to an individual's power to exercise and achieve autonomy.

External influences can also prevent an agent from responding authentically to those reasons that legitimize or invalidate her choices and actions in a number of circumstances that cannot be captured by the specific characteristics of cases like brainwashing, psychological manipulation, deception and lack of self-awareness. For instance, relational theorists of autonomy have argued that internalized oppression and socialization into overly paternalistic, demeaning or unjust interpersonal and social practices can all compromise an agent's power to exercise her autonomy. ${ }^{43}$ In such cases, including Schaefer et al.'s paradigmatic cases of autonomy inhibition, external influences affect an agent's exercise and achievement of autonomy precisely because the causal link between her socio-relational situatedness and her competent, authentic self cannot be neatly delineated. In drawing attention to the social constitution of the self, such cases demonstrate the ways in which an agent's personal identity, character traits and self-understanding (and thereby her motivating attitudes and reasoning processes) are products of motivating social forces over which she has no control in the first instance. ${ }^{44}$ For these reasons, John Christman argues that interpersonal relationships are part of the 'background requirements' for the exercise and achievement of autonomy. ${ }^{45}$

By way of an example that is sympathetic to certain aspects of Schaefer et al.'s rationalistic approach, Diana Meyers analyses the process of constituting an authentic self, whereby social forces continuously interact with an agent's self-conception in the development of her capacity for autonomy, that is, those 'autonomy competencies' that characterize autonomous persons. ${ }^{46}$ Meyers observes that the authentic agent both recognizes and takes responsibility for how social forces shape her cognitive and motivational structure, ${ }^{47}$ which presupposes the same aforementioned cognitive capacities for

\footnotetext{
${ }^{42}$ Ibid: 126.

${ }^{43}$ See, for example, Govier, T. (1993). Self-trust, autonomy, and self-esteem. Hypatia, 8 , 99-120; McLeod, C. (2002). Self-trust and reproductive autonomy. Cambridge, MA: MIT Press; Anderson, J., \& Honneth, A. (2005). Autonomy, vulnerability, recognition, and justice. In J. Christman \& J. Anderson (Eds.), Autonomy and the challenges to liberalism (pp. 127-149). Cambridge, U.K.: Cambridge University Press; Benson, P. (2005). Feminist intuitions and the normative substance of autonomy. In J. S. Taylor (Ed.), Personal autonomy: New essays on personal autonomy and its role in contemporary moral philosophy (pp. 124-142). Cambridge, U.K: Cambridge University Press; Mackenzie, C. (2008). Relational autonomy, normative authority and perfectionism. Journal of Social Philosophy, 39(4), 512-533.

${ }^{44}$ Kong, C. (2017). Mental capacity in relationship: Decision-making, dialogue, and autonomy. Cambridge, U.K.: Cambridge University Press, p. 66.

${ }^{45}$ Christman, J. (2004). Relational autonomy, liberal individualism and the social constitution of selves. Philosophical Studies, 117(1/2), 158.

${ }^{46}$ Meyers, D. (1989). Self, society, and personal choice. New York, NY: Columbia University Press.

${ }^{47}$ Meyers, D. (2000). Intersectional identity and the authentic self? Opposites attract! In C. Mackenzie \& N. Stoljar (Eds.), Relational autonomy: Feminist perspectives on autonomy, agency and the social self (pp. 151-180). Oxford, U.K.: Oxford University Press, p. 159
} 
reason. ${ }^{48}$ However, she also recognizes that the capacity for reason necessary for the exercise of the authentic self can be impaired by oppressive socialization. Thus, Meyers presents a causally relational account of autonomy according to which an agent's ability to develop the capacity for critical reflection that is required for autonomy is contingently dependent upon her interpersonal and social relationships. Oppressive relationships may impair an agent's capacity for autonomy, thereby calling into question the authenticity of the exercise of her autonomy. By contrast, on the basis of a socially embedded conception of agency, interpersonal and social relationships that promote an agent's skills 'to engage in self-discovery, self-definition and self-direction' will, according to Meyers, improve her reasoning capacity and thereby contribute to the emergence and development of the authentic self. ${ }^{49}$

For Meyers, interpersonal and social relationships do not just affect the development of an agent's capacity for reason. She proposes that a certain kind of self-regard is necessary to achieve the self-realization required for autonomy competency. Specifically, such self-regard manifests as affective attitudes of 'self-nurturing', 'self-worth' and 'self-respect'. The point here is that interpersonal relationships mediate an agent's self-understanding and, perniciously or otherwise, causally affect an agent's recognitive relations-to-self, including her recognition of which reasons are relevant to pursuing some ends and not others, and the recognition of her own character, attitudes, and reflections as worthwhile, meaningful and valuable. It is for this reason that, according to Paul Benson, one's authority to speak for one's action-guiding commitments depends on one's having a positive affective attitude towards one's competence and worth. ${ }^{50}$ If reasoning processes do not reflect an agent's respect for herself and for her ability to set her own ends and evaluate the reasons relevant to pursuing some ends and not others, then the power behind the reflective process that gives rise to her behaviour is independent of her authority to self-govern. Owing to the fact that other agents can prevent someone's reasoning from qualifying as a mode of self-government by preventing the reasoner from developing the appropriate self-regarding attitude, relational theorists of autonomy have argued for a basic attitude of self-worth as a necessary but not sufficient condition for the exercise and achievement of autonomy. ${ }^{51}$

In principle, by adopting a reasons-responsive approach to autonomy that requires individuals to assess a wide range of reasons and effectively evaluate the claims of others in a number of situations, Schaefer et al. imply that autonomy can be impaired when interpersonal and social forces influence an agent to such a degree that there is good reason to doubt their power to respond to their action-guiding commitments and to attend to the associated

\footnotetext{
${ }^{48}$ Meyers, op. cit. note 46, pp. 83-84.

${ }^{49}$ Meyers, D. (2005). Decentralizing autonomy: Five faces of selfhood. In J. Anderson \& J. Christman (Eds.), Autonomy and the challenges of liberalism: New essays (pp. 27-55). Cambridge, U.K.: Cambridge University Press, p. 49.

${ }^{50}$ Benson, op. cit. note 43.

${ }^{51}$ Govier, op. cit. note 43; McLeod op. cit. note 43; Anderson \& Honneth, op. cit. note 43; Mackenzie, op. cit. note 43
}

reasons. Doubts can arise not only because of internal factors such as illness, depression, addiction, anxiety and fatigue, but also on the basis of external causal factors such as brainwashing, internalized oppression, stigmatization, disrespectful dialogue or inappropriate normative expectations resulting from previous encounters with overly paternalistic, demeaning or pressurizing institutional practices. Whether an agent's self-regard is nurtured or inhibited is ultimately contingent on her relationships. This receptive dimension of constituting the social agent can also heighten certain inherent vulnerabilities in a dependent relationship. For example, as a result of being in an abusive, subservient relationship, an individual may have no confidence in the decisions she makes, or she may not perceive herself as having the authority to make commitments in the first place. In such circumstances, Catriona Mackenzie claims that even though the agent has the necessary cognitive capacities to reason properly, the exercise of these capacities is compromised such that respecting her decisions and associated reasons would not, in fact, be consistent with respecting her autonomy. ${ }^{52}$ By contrast, exposure to 'relations of care' that nurture our self-regarding attitudes can, according to Camillia Kong, causally contribute to the revision of our perspectives in order to achieve the self-recognitive relationship needed to enable 'a more responsive, confident stance ... towards environmental, social forces in relation to our personal identity'. ${ }^{53}$

Without additional specification, Schaefer et al.'s approach to autonomy inhibition in paradigmatic cases paves the way for a conception whereby not only is the development of an agent's reflective and deliberative autonomy competencies causally dependent upon her interpersonal and social relationships, but the achievement of autonomy necessarily requires an agent to adopt an affective attitude of self-regard, one which is vulnerable to external social influences and recognitive relationships. Consequently, brainwashing, psychological manipulation and deception are not so much problems we can attribute to the individual being brainwashed, manipulated or deceived on the basis of direct and independent cognitive limitations. Rather, paradigmatic cases such as these have important epistemic (and thereby autonomy-affecting) consequences because they are, primarily, socio-relational problems concerned with how individuals relate to themselves in light of interpersonal relationships. ${ }^{54}$ It follows that although reasoning capacity is a necessary condition for autonomous behaviour, the enhancement of this capacity via direct cognitive interventions is, in principle, not a sufficient condition for autonomy enhancement. Furthermore, in order to reliably claim that CE will generally improve autonomy, we would need to establish the workings of the causal systems in which agents are situated, including the internal and external causal factors that influence deliberative processes and self-recognitive affective attitudes. Without such empirical work, generalizations or predictions regarding the

\footnotetext{
${ }^{52}$ Mackenzie, op. cit. note 43, pp. 518-519.

${ }^{53}$ Kong, op. cit. note 44 , p. 85.

${ }^{54}$ For an example of how these paradigmatic cases work in clinical decision-making contexts, see Lewis, J. (2020). Getting obligations right: Autonomy and shared decision making. Journal of Applied Philosophy, 37(1), 118-140.
} 
enhancement of an agent's exercise of their autonomy may lead to the glossing over of important complexities and deviations from standard cases.

If we accept a causally relational approach to autonomy, then a second authenticity issue emerges on the basis of which we can identify the dimensions of autonomy that can and cannot be enhanced. Although, as Schaefer et al. acknowledge, it is reasonable to expect CE to generally enhance an agent's capacity for autonomy, there is a growing body of empirical evidence that suggests that $\mathrm{CE}$ may not even be a necessary condition for the enhancement of an agent's exercise of her autonomy if her cognitively enhanced attitudes and reasoning processes are not seen as acceptable on the basis of the community's normative attitudes to enhancement. ${ }^{55}$ The issue here is that the normative attitudes of those to whom the agent relates can inhibit her self-regarding affective attitudes necessary for self-governing power if she agrees that her cognitively enhanced capacities are, for instance, unfair, undeserved and/or hollow. ${ }^{56}$ In addition, even if a cognitively enhanced agent holds the necessary self-regarding attitudes, the surrounding community's normative attitudes to enhancement can affect an agent's power to exercise her autonomy precisely because the exercise of cognitively enhanced capacities and the associated reasons for or against a specific enhancement-derived action are considered to be unacceptable in certain circumstances. ${ }^{57}$ It has been shown that even though the effect of CE on an individual's performance can be increased when the individual is isolated from external social influences, both individual and collective performance can be reduced, completely eliminated or even reversed when the individual is incorporated within a group. ${ }^{58}$ Thus, the effectiveness of CE in improving both individual and group performance depends on the psychological processes within the group, which, in turn, are guided by the judgments the group members make about CE. Of course, such scenarios ultimately depend upon states of affairs, specifically, the public's attitudes to CE. Nevertheless, research in empirical psychology has revealed that the enhancement concerns of laypeople do, by and large, mirror those raised in expert normative discussions. ${ }^{59}$

\footnotetext{
${ }^{55}$ Faulmüller, N., Maslen, H., \& Santoni de Sio, F. (2013). The indirect psychological costs of cognitive enhancement. American Journal of Bioethics, 13, 45-47; Faber, N., Douglas, T., Heise, F., \& Hewstone, M. (2015). Cognitive enhancement and motivation enhancement: An empirical comparison of intuitive judgments. AJOB Neuroscience, 6(1), 18-20; Faber, N., Häusser, J., \& Kerr, N. (2015). Sleep deprivation impairs and caffeine enhances my performance, but not always our performance: How acting in a group can change the effects of impairments and enhancements. Personality and Social Psychology Review, 21(1), 3-28.

${ }^{56}$ Faber, N., Savulescu, J., \& Douglas, T. (2016). Why is cognitive enhancement deemed unacceptable? The role of fairness, deservingness, and hollow achievements. Frontiers in Psychology, 7(232), 1-12.

${ }^{57}$ Conrad, E., Humphries, S., \& Chatterjee, A. (2019). Attitudes toward cognitive enhancement: The role of metaphor and context, AJOB Neuroscience, 10(1), 35-47.

${ }^{58}$ Faber et al., op. cit. note 55 .

${ }^{59}$ Fitz, N., Nadler, R., Manogaran, P., Chong, E., \& Reiner, P. (2013). Public attitudes toward cognitive enhancement. Neuroethics, 72, 173-88; Schelle, K., Faulmüller, N., Caviola, L., \& Hewstone, M. (2014). Attitudes toward pharmacological cognitive enhancement - a review. Frontiers in Systems Neuroscience, 8, 53.
}

\section{5 | CONCLUSION}

How should we interpret the claim that CE can enhance autonomy? When Schaefer et al. argue that CE can enhance autonomy, their argument is concerned primarily with the enhancement of an agent's capacity for autonomy. If we assume that the concept of autonomy refers merely to the capacity for autonomy, of which reasoning capacity is a necessary condition, then their argument that CE generally enhances autonomy seems plausible. Insofar as it seems plausible that, by enhancing reasoning capacity, the capacity for autonomy is generally enhanced, then, following Earp, Douglas and Savulescu's comments regarding capacity-oriented enhancement, we can reasonably claim that CE facilitates autonomy in this specific sense. ${ }^{60}$ However, the aim of this paper has been to develop a more complete understanding of autonomy and its relation to CE. Does CE enhance autonomy, tout court? As we have seen, it does not. Given that the exercise and achievement of autonomy is not equivalent to a mere cognitive capacity rooted in purely neurological phenomena, there are limits to what dimensions of autonomy can be enhanced by direct cognitive interventions.

If we are concerned with whether cognitively enhanced individuals reason and behave more autonomously, then we need to consider questions of authenticity. Although this paper has not attempted to offer a bioconservative thesis, it has questioned whether $\mathrm{CE}$ is, in fact, capable of enhancing an agent's authentic exercise of her capacity for reason. In light of Schaefer et al.'s claims regarding autonomy inhibition and the causally relational dimension of autonomy that these claims invoke, this paper has demonstrated that the enhancement of reasoning capacity via direct cognitive interventions is, in principle, not a sufficient condition for autonomy enhancement. Furthermore, there is empirical evidence to suggest that the enhancement of reasoning capacity may not even be a necessary condition for the enhancement of an agent's exercise of her autonomy.

The approach taken in this paper complements that taken by Schaefer et al. The upshot of both of these approaches is that we must be careful to qualify the claim that CE enhances autonomy by specifying which dimensions of autonomy can and cannot, in principle, be enhanced via direct cognitive interventions. Without sufficient qualification, promoting $\mathrm{CE}$ as an autonomy enhancer not only could set unreasonable expectations for would-be consumers, but also could foster a competitive social environment in which those that either refuse $\mathrm{CE}$, or do not have the economic means to pursue it, end up socio-economically disadvantaged (even if CE does not, in fact, enhance autonomy). ${ }^{61}$ What this paper has shown is that CE may facilitate an agent's capacity to be less affected by objects of volition that would otherwise inhibit her capacity for autonomy. However, this is not equivalent to affecting the exercise of her autonomy; on its own, CE does not determine the ways in which an

\footnotetext{
${ }^{60}$ Earp et al., op. cit. note 32 .

${ }^{61}$ Bostrom, N., \& Sandberg, A. (2009). Cognitive enhancement: Methods, ethics, regulatory challenges. Science and Engineering Ethics, 15(3), 311-341.
} 
agent actually responds to reasons, her own character and her own attitudes in the ways necessary for genuine self-governance.

\section{ACKNOWLEDGEMENTS}

A draft of this paper was presented at the Political Theory \& Philosophy Seminar series at Queen's University Belfast. I wish to thank Keith Breen, Ruth Hewitson and Tom Walker for their excellent suggestions in relation to the article's fundamental aims and arguments. I am immensely grateful to Julian Savulescu for his detailed and critical response to a draft of this article, especially for elaborating on his views regarding the relationship between cognitive enhancement and autonomy. I also gratefully acknowledge the respective contributions of the two anonymous reviewers at Bioethics. Finally, I am indebted to Clancy Pegg for, in my opinion, going above and beyond the call of duty to ensure that this article sees the light of day.

\section{CONFLICT OF INTEREST}

The author declares no conflict of interest.

\section{ORCID}

Jonathan Lewis iD https://orcid.org/0000-0001-8342-1051
Jonathan Lewis is a postdoctoral fellow at Dublin City University. His interests include the ethics of new and emerging healthcare technologies as well as issues concerning clinical decision-making, patient autonomy and the empowerment of vulnerable individuals. He also employs methods in experimental philosophy ('x-phi') to shed light on normative and conceptual questions concerning clinical practice and biomedical technologies.

How to cite this article: Lewis J. Autonomy and the limits of cognitive enhancement. Bioethics. 2020;00:1-8. https://doi. org/10.1111/bioe.12791 